\title{
Reactivity and Free Radical Chemistry of Lilac (Syringa Vulgaris) Charcoal
}

\section{Nyombi A ${ }^{a}$, Williams R. Mike ${ }^{b}$, Wessling R $^{\mathbf{a}}$}

${ }^{a}$ Cranfield Forensic Institute, Defense Academy of the UK, Cranfield University, Shrivenham, SN6 8LA

${ }^{\mathrm{b}}$ Centre for Defense Chemistry, Defense Academy of the UK, Cranfield University, Shrivenham, SN6 8LA

\section{Graphical Abstract}

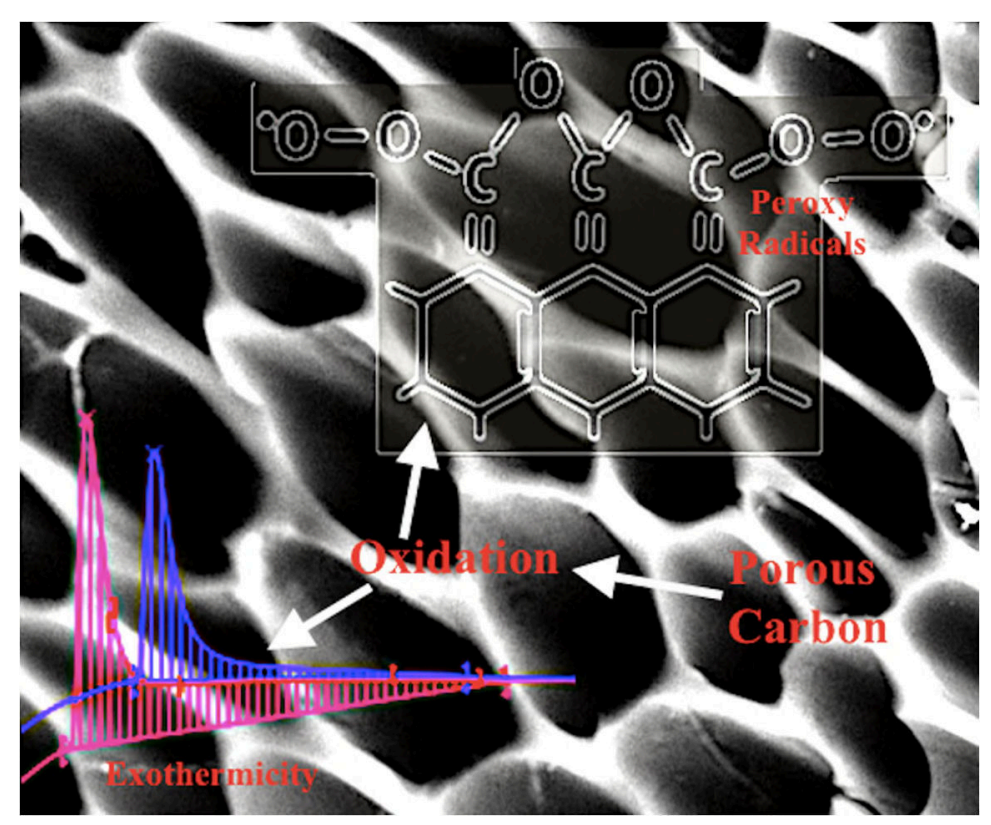

\section{HIGHLIGHTS}

○ Lilac ignites quickly $\left(250-290^{\circ} \mathrm{C}\right)$, and has a narrow combustion temperature range $(300-$ $\left.520^{\circ} \mathrm{C}\right)$,

- It is microporous with a surface area of $4.3706 \mathrm{~m}^{2} / \mathrm{g}$,

- Lilac has $\mathrm{C}-\mathrm{C}$ free radicals arising from carbonization,

- It forms peroxyl radicals on oxidation in air,

$\circ$ Degassing in $\mathrm{N}_{2}$ and acid washing removes the free radicals. 


\section{ABSTRACT}

The reactivity, porosity and surface chemistry of charcoal determine its combustion behaviour, and these properties depend on the source of the original wood, production conditions and treatment. Here we studied the properties of charcoal derived from lilac (Syringa vulgaris). Its reactivity was tested by isothermal and non-isothermal thermogravimetric analysis and differential scanning calorimetry in air and nitrogen. Its porosity was tested by monitoring nitrogen adsorption at $77 \mathrm{~K}$. The free radical concentration was determined by measuring the electron spin resonance of fresh charcoal, after washing with $\mathrm{HCl}$, and after degassing in air with or without nitrogen. We found that lilac has a specific surface area of $4.3706 \mathrm{~m}^{2} / \mathrm{g}$ and is highly reactive, igniting at $250-300{ }^{\circ} \mathrm{C}$ with peak combustion at $320-520^{\circ} \mathrm{C}$. The quantity of oxygen consumed and heat released during oxidation increased with temperature. The free radical concentration in the fresh charcoal was $5.29 \times 10^{18} \mathrm{spins} / \mathrm{g}$, compared to $3.49 \times 10^{19} \mathrm{spins} / \mathrm{g}$ after acid washing, $7.06 \times 10^{19} \mathrm{spins} / \mathrm{g}$ after exposure to air, and $3.75 \times 10^{17}$ spins/g after degassing with nitrogen before exposure to air. The line width of all the charcoal samples was 11.6-11.9 G. However, degassing the charcoal in nitrogen followed by exposure to air at low temperatures resulted in a four-fold increase in the line width to $41.8 \mathrm{G}$. The exposure of lilac charcoal to air alone at low temperatures resulted in the formation of persistent peroxyl radicals superimposed on the main peak. The g-values of charcoal samples that were fresh, acid washed, degassed in $\mathrm{N}_{2}+$ air, and degassed in air alone (main peak) were 2.00481, 2.00477, 2.00260 and 2.00483, respectively. The corresponding g-values of the peroxyl radicals superimposed on the main peak were $2.0155,2.0138,2.0020$ and 2.0007 , respectively. The reactivity, free radical content and specific surface area suggest that lilac charcoal is particularly suitable for applications involving energetic materials, catalysis and co-firing.

Keywords: Lilac (Syringa vulgaris) charcoal, reactivity, porosity, oxygen consumption, heat release, electron spin resonance, peroxyl radicals

\section{INTRODUCTION}

Charcoal is widely used for heating and cooking, but the properties of charcoal depend on its source, production conditions and treatment, which define its reactivity, porosity and surface chemistry. Charcoal oxidation is a complex process which influences combustion and gasification. Oxidation rates are partially influenced by surface functional groups and 
reactions catalysed by mineral components, and such catalytic effects have also been observed during pyrolysis [1]. The oxidation of charcoal includes steps such as the adsorption of oxygen, the chemisorption of oxygen at carbon active sites to form complexes, migration to form low activation energy complexes, and the desorption of the complexes as gaseous products such as $\mathrm{CO}$ and $\mathrm{CO}_{2}$ [2]. Physisorption is usually reversible, whereas chemisorption may involve free-site reactants and stable-oxide-site reactants. Together, these steps are affected by the properties of the char, the reaction temperature, the oxygen concentration, the char particle size, and the reactor type.

At low and high temperatures, oxygen almost completely penetrates the charcoal particle before the onset of significant oxidation. At temperatures $<900 \mathrm{~K}$, the specific surface area of char changes as predicted by random pore models [3]. The reactivity of char under both oxidizing and inert conditions has been studied by thermogravimetric analysis $[4,5]$. The porosity of charcoal is partly caused by the mineral content incorporated into trees, which depends on the growth location, climate, and cropping [6]. The mineral elements are responsible for preferential gasification during activation, creating mesopore and macropore channels and pitting. Free radicals generated during pyrolysis and carbonization can introduce considerable strain energy into the lattice. The cellulosic structure loses small molecules such as water and $\mathrm{CO}_{2}$ together with more complex aliphatic acids, carbonyls, and alcohols. The resulting chemically-reactive lattice encloses the vacancies created by the loss of volatiles. The new lattice is continuously refined, but typically has high $\mathrm{C} / \mathrm{H}$ and $\mathrm{C} / \mathrm{O}$ ratios due to the preferential loss of hydrogen and oxygen. With increasing temperature, the unstable carbon network becomes more carbonaceous and more aromatic as the carbon atoms re-adjust their positions and approximate to the six-membered ring system comprising the building blocks of lamellar constituent molecules (LCMs). Further heat treatment removes more hydrogen, oxygen and nitrogen, causing the network to become more carbonaceous and aromatic.

The ring system and random bonding reduce the density of charcoal to $1.0 \mathrm{~g} / \mathrm{cm}^{3}$, which is significantly lower than that of single-crystal graphite $\left(2.267 \mathrm{~g} / \mathrm{cm}^{3}\right)$. The spaces between these bonded LCMs constitute the microporous structures of the charcoal, and during pyrolysis and carbonization, mesopores and macropores develop within the char matrix due to shrinkage [7]. Surface groups on the charcoal (including hydroxyl, carboxyl, carbonyl, ether and lactone structures) play a significant role during combustion [8] [9]. All these 
functional groups influence the reaction of charcoal and free radicals, the latter being responsible for the initiation and termination of chain reactions. The nature and content of these free radicals in charcoal must be characterized in order to understand the reactivity of charcoal in different environments.

Electron spin resonance (ESR) spectroscopy is often used to determine the organic free radical content of carbon materials [10], [11], [12]. However, peroxyl radicals do not form a defined ESR spectrum and are difficult to interpret [13], [14]. The primary bonding of peroxyl radicals results from Lewis acid-base reactions between diamagnetic $\mathrm{R}$ groups and $\mathrm{O}^{+}$or $\mathrm{O}^{-}$radicals. The unoccupied $\pi^{*}$ orbital in $\mathrm{O}_{2}{ }^{+}$is an electron acceptor which acts as a Lewis $\sigma$ acid, whereas the filled level of $\mathrm{O}_{2}{ }^{-}$is an electron donor or Lewis $\sigma$ base [15]. ESR spectroscopy is the most powerful technique for the structural characterization of paramagnetic systems because it is a non-invasive method hence the samples are not damaged. With free radicals as molecular probes, ESR spectroscopy is ideal for the analysis of the structural features of diamagnetic nanoscale and supramolecular structures and surfaces. Unlike other spectroscopic parameters, ESR transitions are characterized by tiny energy gaps (and consequently very long wavelengths). The small populations of the different energy levels $\left(10^{-3}\right.$ to $\left.10^{-1} \mathrm{~kJ} / \mathrm{mol}\right)$ limit the sensitivity of the technique, but it still outperforms nuclear magnetic resonance (NMR) spectroscopy [16]. For continuous wave ESR, some of the more important features include the position, separation, number of lines, line width, and intensity. The $g$-value determines the position, the separation is determined by the hyperfine coupling constant or $a$-value, and the number of lines in the hyperfine pattern is dictated by the nuclear spin $I$. The line width may be a consequence of dynamic effects or unresolved hyperfine interactions. The line intensities may be due to the multiplicity of the hyperfine lines caused by multiple interactions with nuclei of $\geq 1 / 2$, or the anisotropy of the paramagnetic system [16].

Here we set out to determine the oxidation properties of lilac (Syringa vulgaris) charcoal in air under both isothermal and non-isothermal conditions. We also determined the specific surface area of the charcoal using nitrogen adsorption at $77 \mathrm{~K}$ and evaluated the free radical type and content for natural, pyrolyzed and oxidized charcoal. 


\section{METHODOLOGY}

\subsection{Charcoal sample preparation}

The charcoal used in this study was produced in the laboratory from lilac (S. vulgaris) wood at $500{ }^{\circ} \mathrm{C}$. The samples were ground in an Essa LM2 pulverizing mill and sieved to $<200 \mu \mathrm{m}$ particle size. Four portions of the ground charcoal were prepared under different conditions:

i. $\quad$ Sample (A): 5-10 mg of charcoal was pyrolyzed on a Mettler Toledo TGA/DSC 3+ device under $\mathrm{N}_{2}(50 \mathrm{ml} / \mathrm{min})$ at a heating rate of $20^{\circ} \mathrm{C} / \mathrm{min}$ from $30{ }^{\circ} \mathrm{C}$ to $750{ }^{\circ} \mathrm{C}$, then cooled under $\mathrm{N}_{2}$ to a desired test isothermal temperature and then exposed to air $(50 \mathrm{ml} / \mathrm{min})$ at that isothermal for 30 minutes.

ii. Sample (B): $5-10 \mathrm{mg}$ of charcoal was pyrolyzed under $\mathrm{N}_{2}\left(50 \mathrm{ml} / \mathrm{min} ; 30-750^{\circ} \mathrm{C}\right)$, then cooled under $\mathrm{N}_{2}$ to $30^{\circ} \mathrm{C}$.

iii. Sample (C): $5-10 \mathrm{mg}$ of charcoal was oxidized in air $(50 \mathrm{ml} / \mathrm{min})$ at $100{ }^{\circ} \mathrm{C}$ for 300 $\min$.

iv. Sample (D): $5-10 \mathrm{mg}$ of charcoal was oxidized under air $\left(50 \mathrm{ml} / \mathrm{min} ; 30-650{ }^{\circ} \mathrm{C}\right)$ to evaluate its reactivity kinetics with air (oxygen).

v. Sample (E): 5-10 mg of commercial activated carbon samples were also analysed for comparison.

\subsection{Elemental and proximate analysis}

Elemental analysis for carbon, hydrogen and nitrogen, and proximate analysis, were carried out as we previously described [4]. The quantities of elements present in the charcoal ash as oxides were analysed using a Seiko Instruments SEA6000VX bench-top X-ray fluorescence detector (Nanotechnology Incorporated) using a sample standard (RTC-CRM002-100G from LGC) and a rhodium tube as the target. The measurement time was $100 \mathrm{~s}$ with a collimator/spot size of $1.2 \times 1.2 \mathrm{~mm}$, a tube voltage of $50 \mathrm{kV}$, a tube current of $314 \mu \mathrm{A}$ in auto mode, no filter and a helium purging environment.

\subsection{Specific surface area}

Nitrogen adsorption experiments at $77 \mathrm{~K}$ were conducted to determine the specific surface area of the test samples using a Quantachrome Nova-1200 instrument. The Brunauer, 
Emmett, and Teller (BET) model was applied to fit the nitrogen adsorption isotherms and evaluate the specific surface area of the charcoal samples [17].

\subsection{ESR spectroscopy}

Continuous wave ESR was performed in the X-band of the microwave frequency and ESR spectra were recorded on a JES-FA Series ESR spectrometer (Jeol Ltd, Tokyo, Japan) as previously described [12]. Samples were placed in a closed-bottom quartz capillary tube with a wall thickness of $0.75 \mathrm{~mm}$ and an outer diameter of $5 \mathrm{~mm}$. The measurements were carried out at room temperature with a microwave power of $1 \mathrm{~mW}$, a modulation width of $0.014 \mathrm{mT}$, a sweep width of $75 \mathrm{G}$, a sweep time of $2 \mathrm{~min}$, and a time constant of $0.3 \mathrm{~s}$. The spin concentrations (spins/g) of the samples were computed as described elsewhere [10]. DPPH was used as a standard to determine the spin concentration of radicals.

\subsection{Oxidation/reactivity kinetics}

\subsubsection{Non-isothermal oxidation}

The kinetics of non-isothermal oxidation in the air (using sample D - described in 2.1 above) was determined using the Kissinger, Kissinger-Akahira-Sunose (KAS), and Flynn-WallOzawa (FWO) methods.

The Kissinger method [18] is model-free but it is not an iso-conventional method because it assumes constant activation energy during conversion. It was derived by assuming that the rate of oxidation follows first-order kinetics [19] although this may not always be the case, and it takes the form shown in Equation 1.

$$
\operatorname{In}\left(\frac{\beta}{T^{2} \max }\right)=\left(-\frac{E a}{R}\right)\left(\frac{1}{T \max }\right)+\frac{\operatorname{InAR}}{E a}
$$

Different heating rates $\left(\beta=\beta_{1}, \beta_{2}, \ldots\right)$ were used during the measurements. The apparent activation energy was determined from the plot of $\operatorname{In} \beta / \mathrm{T}^{2}{ }_{\max }$ versus $1 / \mathrm{T}_{\max }$.

The Kissinger-Akahira-Sunose (KAS) method is based on Equation 2;

$$
\operatorname{In}\left(\frac{\beta}{T^{2}}\right)=\left(-\frac{E a}{R}\right)\left(\frac{1}{T}\right)+\frac{\operatorname{InAR}}{\operatorname{Eag}(\alpha)}
$$


where $g(\alpha)$ is the integral conversion function [20]. For constant conversion, the apparent activation energy was determined from the plot of $\operatorname{In} \beta / \mathrm{T}^{2}$ versus $1 / \mathrm{T}$.

The Flynn-Wall-Ozawa (FWO) method was developed by Flynn \& Wall [21] and Ozawa [22], based on Doyle's approximation [23]. It was derived from the integral function shown in Equation 3.

$$
g(\alpha)=\int_{0}^{\alpha} \frac{d \alpha}{f(\alpha)}=\frac{A}{\beta} \int_{T o}^{T} e^{-\left(\frac{E}{R T}\right)} d T
$$

Equation 3 does not have an analytical solution. Doyle calculated $\operatorname{lng}(\alpha)$ values for a wide range of $(\mathrm{Ea} / \mathrm{RT})$ values, and found that within the limits $20 \leq(\mathrm{Ea} / \mathrm{RT}) \leq 60[24]$, the approximation shown in Equation 4 can be derived by rearrangement.

$$
\operatorname{In} \beta=\operatorname{In}\left(\frac{A E a}{R g(\alpha)}\right)-5.331-1.052\left(\frac{E a}{R T}\right)
$$

The plot of $\operatorname{In} \beta$ versus $1 /$ T gives a straight line whose slope $-1.052\left(\frac{E a}{R}\right)$ is used to determine the activation energy.

\subsubsection{Isothermal oxidation}

The first part of the oxygen adsorption experiments was performed using 'cleaned' charcoal, i.e. the charcoal was pyrolyzed in nitrogen $\left(30-750{ }^{\circ} \mathrm{C}\right)$ and cooled in nitrogen to a desired isothermal temperature and then exposed to air at that isothermal for $30 \mathrm{~min}$. The second part was performed using fresh charcoal, i.e. the samples were exposed to air $\left(30-100{ }^{\circ} \mathrm{C}\right)$ at a rate of $20^{\circ} \mathrm{C} / \mathrm{min}$ and then kept in air at $100{ }^{\circ} \mathrm{C}$ for $30 \mathrm{~min}$. In both cases, samples were analysed by ESR spectroscopy for the presence of free radicals, and to determine the amount of oxygen adsorbed/consumed and the adsorption rates.

\section{RESULTS AND DISCUSSION}

\subsection{Elemental composition and proximate analysis}

Proximate analysis revealed that lilac charcoal has a moisture content of $3.46 \pm 0.01 \%$, and comprises $11.71 \pm 0.01 \%$ volatile matter, $80.88 \pm 0.03 \%$ fixed carbon and $3.95 \pm 0.01 \%$ ash. Elemental analysis showed that lilac charcoal is composed primarily of $\mathrm{C}, \mathrm{H}$, and $\mathrm{O}$ with traces of $\mathrm{N}$, specifically $83.44 \pm 0.46 \% \mathrm{C}, 2.74 \pm 0.14 \% \mathrm{H}, 13.21 \pm 0.48 \% \mathrm{O}$ and $0.62 \pm 0.11 \% \mathrm{~N}$ 
by weight. The $\mathrm{O} / \mathrm{C}$ and $\mathrm{H} / \mathrm{C}$ atomic ratios were 0.158 and 0.033 , respectively. The high $\mathrm{O} / \mathrm{C}$ ratio suggests that lilac charcoal is very reactive, which is consistent with the experimental observations discussed below. The mineral content of the charcoal was $43.8 \% \mathrm{SiO}, 29.8 \%$ $\mathrm{CaO}, 13.8 \% \mathrm{P}_{2} \mathrm{O}_{5}, 10.6 \% \mathrm{~K}_{2} \mathrm{O}, 0.9 \% \mathrm{FeO}, 1.2 \% \mathrm{MgO}$ and $0.7 \% \mathrm{Al}_{2} \mathrm{O}_{3}$ by weight, which is associated with the growth location, climate, and cropping [6].

The $\mathrm{H} / \mathrm{C}$ ratio correlated with the oxidative reactivity of the charcoal particles, reflecting the high probability of $\mathrm{H}$ abstraction by $\mathrm{O}_{2}$ or the radicals present in the combustion environment such as ${ }^{\bullet} \mathrm{H},{ }^{\bullet} \mathrm{OH},{ }^{\bullet} \mathrm{CH}_{3}$ and ${ }^{\bullet} \mathrm{C}_{3} \mathrm{H}_{3}$ to create radical sites on the charcoal to facilitate $\mathrm{O}_{2}$ adsorption, thus increasing the oxidation rate [25].

\subsection{Oxidation/reactivity}

\subsubsection{Non-isothermal oxidation}

Figure 1 shows the conversion of charcoal and its reactivity in the air at different heating rates. The conversion rates were unimodal at all heating rates. The temperatures corresponding to $50 \%$ conversion were $447.8,428.8,416.6$ and $403.5{ }^{\circ} \mathrm{C}$ for $15,10,5$ and 2 ${ }^{\circ} \mathrm{C} / \mathrm{min}$, respectively, and the temperatures corresponding to maximum conversion were $482.8,458.8,447.0$ and $420.4^{\circ} \mathrm{C}$.

Significant charcoal oxidation started at $250-300{ }^{\circ} \mathrm{C}$, lower than the temperatures typically associated with the loss of physically-bound and chemically-bound moisture as well as unstable volatiles. The oxidation took place in a narrow temperature range (mainly 330-520 ${ }^{\circ} \mathrm{C}$ ) for all heating rates, suggesting that lilac charcoal is mostly composed of monomeric carbonaceous units, i.e. fragments of randomly curved carbon sheets containing pentagonal and heptagonal rings dispersed throughout a hexagonal network [26]. However, the reactivity could also reflect the size of the polycyclic aromatic hydrocarbon units, the presence of oxygenated or aliphatic functional groups, the presence of active sites, the $\mathrm{H} / \mathrm{C}$ ratio, the presence of free radicals, and the bonding between each unit. The high reactivity could also be due to the presence of many exposed carbon atoms on the surface and between the pores which are susceptible to oxidation.

The pre-exponential factor $A$ is proportional to the frequency of collision between active sites on charcoal and oxygen. Low $A$ values indicate complex active sites [25]. Table 1 shows that the A values for lilac charcoal were in the range $10^{2}-10^{7}$, indicating that the active sites on 
charcoal may be complex, possibly composed of polycyclic aromatic hydrocarbons with oxygen heteroatoms. The activation energy $\left(E_{a}\right)$ values for oxidation in air were 110-145 $\mathrm{kJ} / \mathrm{mol}$, which is narrow compared to other carbons [27]. Also, we observed a drop in the $E_{\mathrm{a}}$ and $A$ values during the progress of oxidation (Figure 1 and Table 1), implying the progressive formation of weaker bonds [28]. However, the complexity of the active sites seems to increase with conversion, possibly due to pentagonal and hexagonal ring opening and the formation of reactive oxygen species which later form carbon oxides.
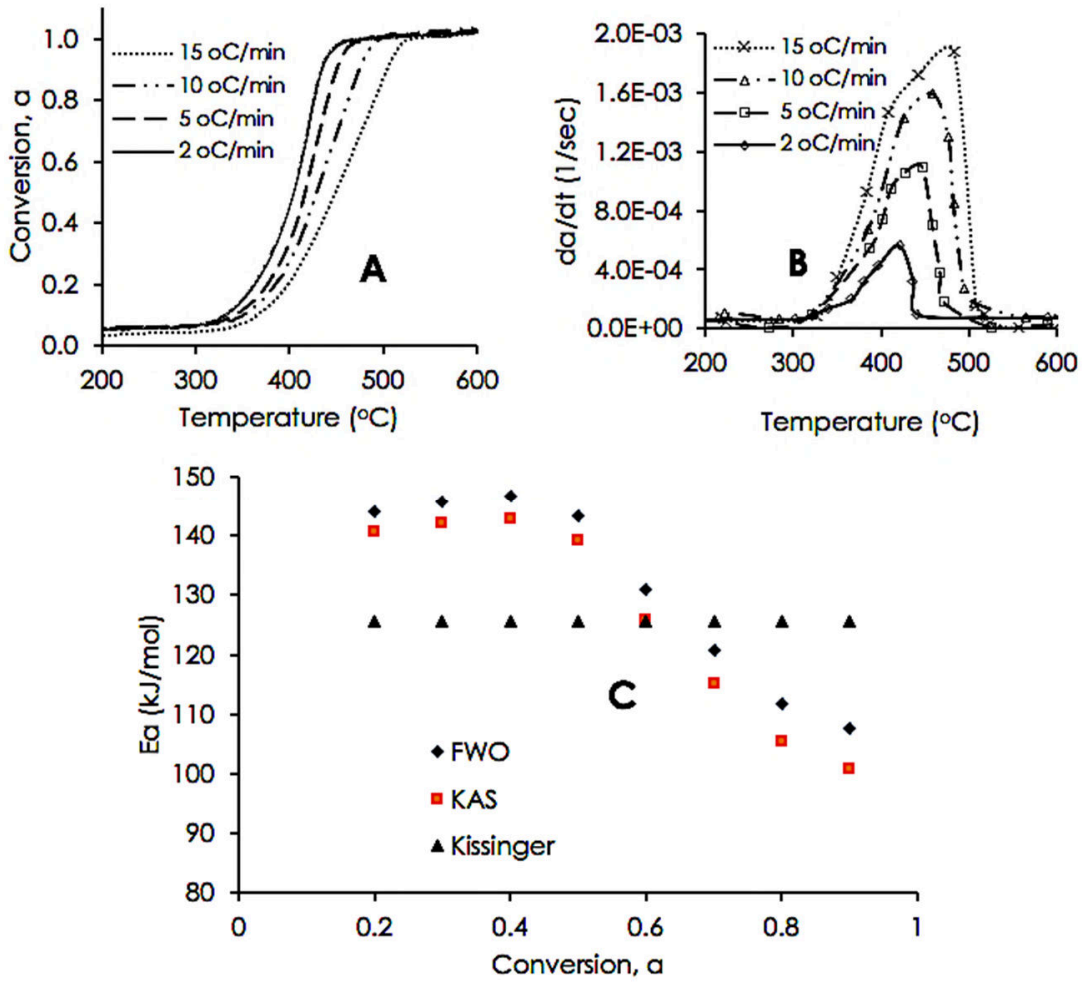

Figure 1: Conversion (A) and reactivity (B) and Ea of lilac charcoal

Table 1: Pre-exponential factors for the oxidation of charcoal

\begin{tabular}{|l|l|l|l|}
\hline Conversion & Pre-exponential factors $(1 / \mathrm{s})$ \\
\hline$\alpha$ & FWO & KAS & Kissinger \\
\hline 0.2 & $7.77 \times 10^{13}$ & $3.55 \times 10^{7}$ & $4.79 \times 10^{5}$ \\
\hline 0.3 & $4.29 \times 10^{13}$ & $1.89 \times 10^{7}$ & $4.79 \times 10^{5}$ \\
\hline 0.4 & $2.45 \times 10^{13}$ & $1.05 \times 10^{7}$ & $4.79 \times 10^{5}$ \\
\hline 0.5 & $7.45 \times 10^{12}$ & $2.92 \times 10^{6}$ & $4.79 \times 10^{5}$ \\
\hline 0.6 & $4.82 \times 10^{11}$ & $1.51 \times 10^{5}$ & $4.79 \times 10^{5}$ \\
\hline 0.7 & $4.79 \times 10^{10}$ & $1.23 \times 10^{4}$ & $4.79 \times 10^{5}$ \\
\hline 0.8 & $5.47 \times 10^{9}$ & $1.16 \times 10^{3}$ & $4.79 \times 10^{5}$ \\
\hline 0.9 & $1.02 \times 10^{9}$ & $1.0 \times 10^{2}$ & $4.79 \times 10^{5}$ \\
\hline
\end{tabular}




\subsubsection{Isothermal oxidation}

When the charcoal was pyrolyzed in nitrogen, then cooled in nitrogen to the desired temperature, followed by exposure to air for $30 \mathrm{~min}$, we observed a mass gain implying that oxygen was absorbed from the air (Figure 2). Activating carbon in argon and then oxidizing it with an oxygen/argon mixture previously yielded diffuse reflectance infrared fourier transform (DRIFT) spectra indicating the formation of oxygen functional groups on the carbon surface [29]. The functional groups were assigned to cyclic anhydrides, lactones, ethers, and phenols. The adsorption and reaction of ozone molecules on the surface of the carbon yields free radicals on the surface, which may be any oxygen-containing active species [30]. Similarly, the oxidation of carbon black with ozone and $\mathrm{NO}_{2}$ forms carboxylic, phenolic, and lactonic groups on the carbon surface [31].

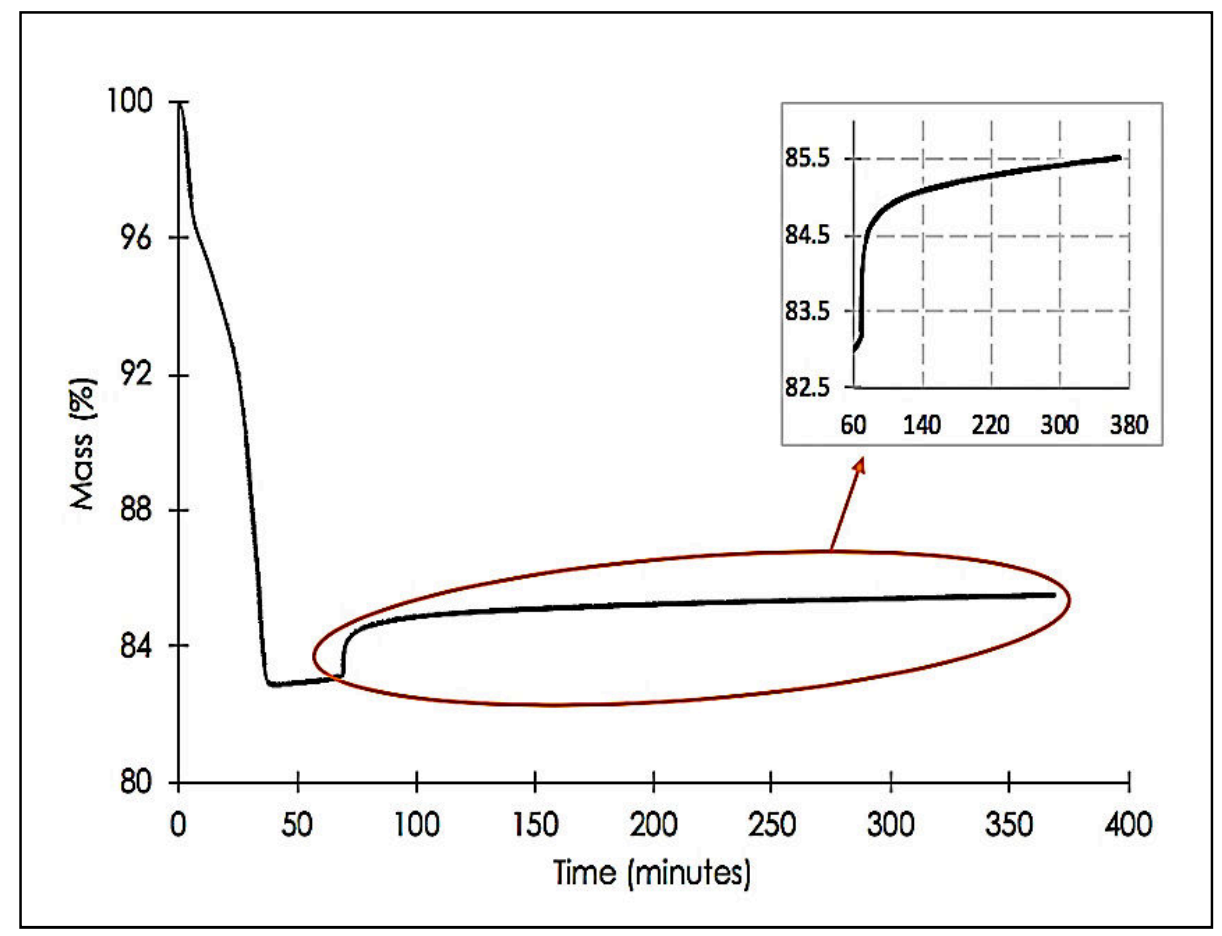

Figure 2: Mass gain of charcoal pyrolyzed in $\mathrm{N}_{2}\left(50-600^{\circ} \mathrm{C}\right)$ and then exposed to air at $100^{\circ} \mathrm{C}$.

\subsubsection{Adsorption rate}

Figure 3 shows that the initial adsorption rate is a steep gradient that follows zero-order kinetics at all temperatures, meaning that the amount adsorbed is dependent neither on the amount of carbon in the system nor the concentration of oxygen (air containing $21 \%$ oxygen was used in all the experiments). The subsequent decay followed first-order kinetics, implying that the active sites on the carbon surface and the oxygen concentration both played 
a role. At low temperatures $\leq 250^{\circ} \mathrm{C}$, the decline could be attributed to the loss of active sites available for further adsorption.

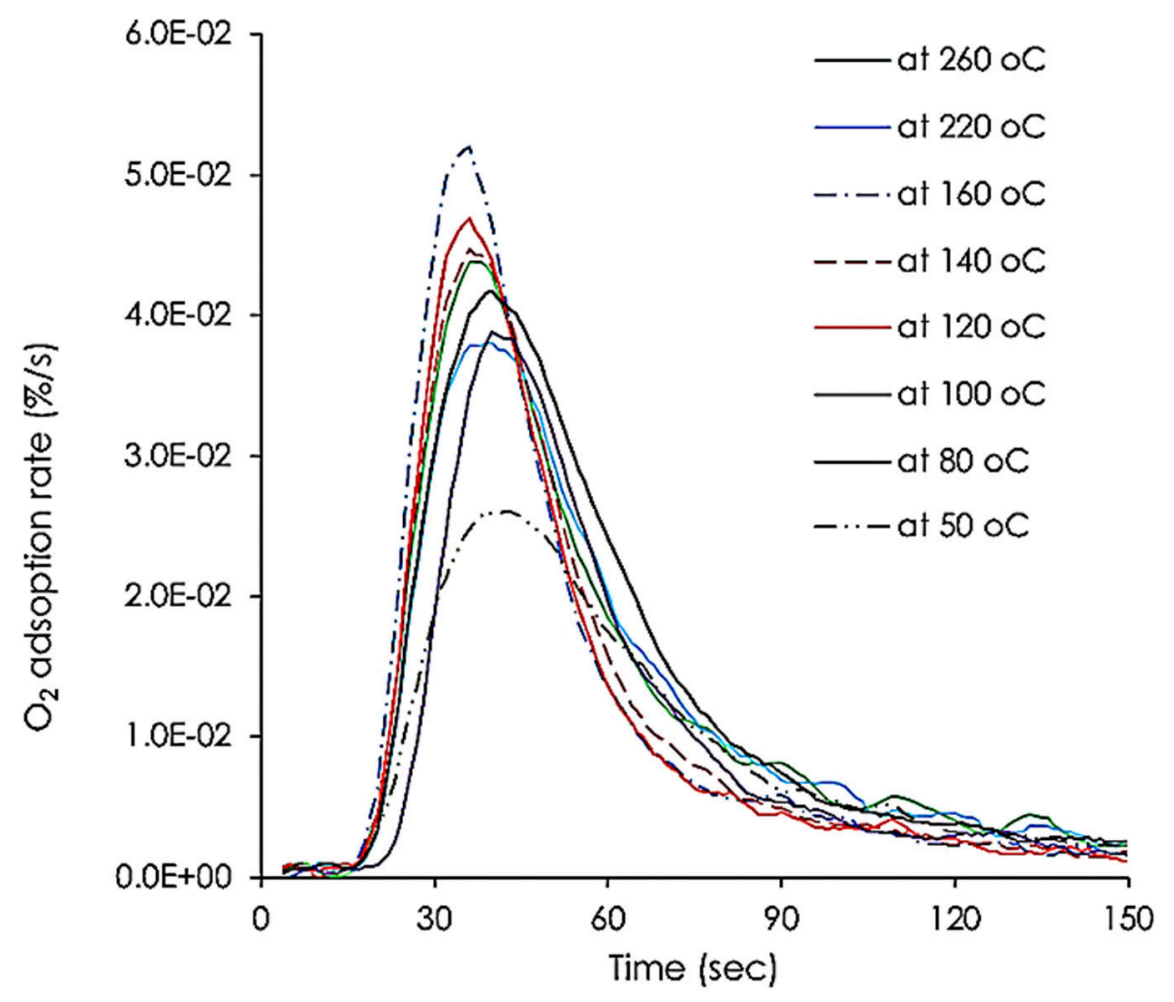

Figure 3: Rate of adsorption of oxygen on clean charcoal surfaces over the temperature range $50-260{ }^{\circ} \mathrm{C}$.

The area under the normalized oxygen adsorbed/consumed versus time curve gives the total amount of oxygen consumed at different temperatures. We found that the charcoal continued to adsorb/consume more oxygen as the temperature increased. Figure 4 shows that the computed amounts of oxygen consumed increased exponentially as a function of temperature. This was previously observed during the oxidation of isomeric hexanes, and compounds with more tertiary $\mathrm{C}-\mathrm{H}$ bonds showed a greater stability than those with more secondary $\mathrm{C}-\mathrm{H}$ bonds due to the formation of ketone rather than aldehyde groups [32]. These observations are also in agreement with the data reported by Dollimore and colleagues [8]. 


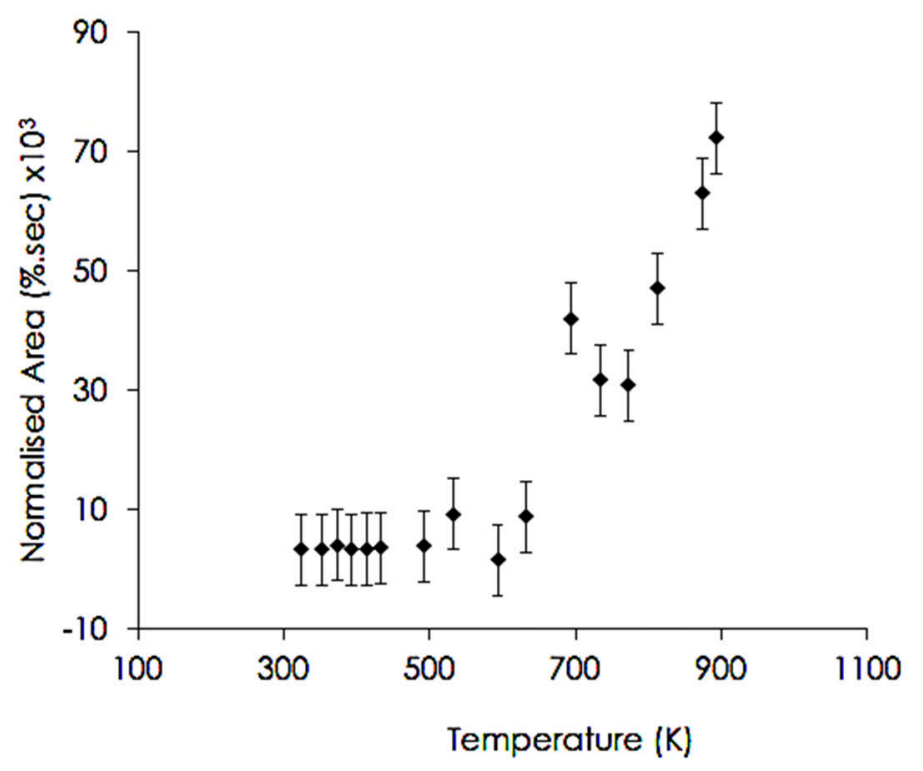

Figure 4: Amount of oxygen consumed at different temperatures.

\subsubsection{Exothermicity of isothermal oxidation}

As expected, we found that the adsorption of oxygen to charcoal was an exothermic process. Figure $5 \mathrm{~A}$ shows the integration of exotherms for oxygen adsorption at 50 and $160{ }^{\circ} \mathrm{C}$ to estimate the amount of liberated heat. The exothermicity of oxygen adsorption increased exponentially with temperature (Figure 5B). As discussed above, the amount of oxygen consumed also increased with temperature, and given that oxygen supports burning, the greater the consumption the more heat is generated.
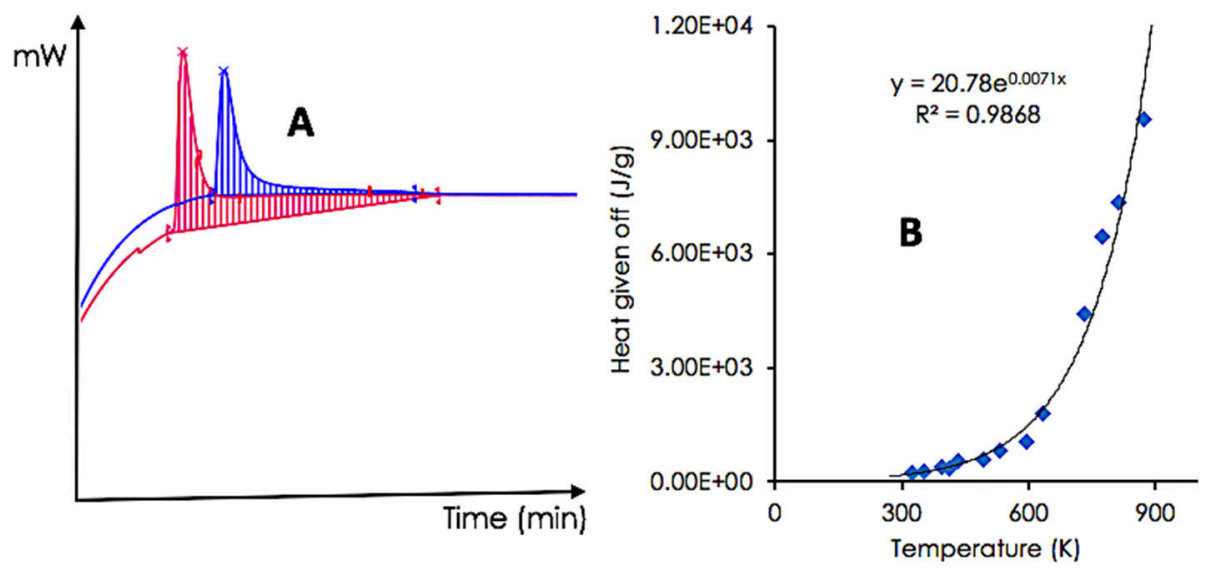

Figure 5: Exothermicity of oxygen adsorption. A-Peak integrals (blue at $50^{\circ} \mathrm{C}$ and red at $160^{\circ} \mathrm{C}$ ). B-Heat given off at different temperatures. 


\subsection{The porosity of lilac charcoal}

Microscopy revealed that lilac chars retain the parent wood porosity even after carbonization (results not shown). The charcoal used in this study was produced from wood pyrolyzed at $500{ }^{\circ} \mathrm{C}$ in the laboratory.

\subsubsection{Nitrogen adsorption isotherm}

Nitrogen adsorption was tested with nitrogen gas at a maximum manifold pressure of $925 \mathrm{mmHg}$, a non-ideality factor of 0.000062 , a density conversion factor of 0.0015468 , and nitrogen molecular cross-sectional area of $0.162 \mathrm{~nm}^{2}$. A five-point program was used, and the resulting isotherm is shown in Figure 6A. This type of isotherm is typical of microporous materials with a small external surface area. The initial steep step at low $\mathrm{P} / \mathrm{P}^{0}$ is due to the filling of very narrow pores, and the limiting uptake is dependent on the accessible micropore volume [33].

The specific surface area of the charcoal was calculated by summing the adsorbed amounts as described by the Brunauer, Emmett and Teller (BET) equation, in Equation 5.

$$
\frac{P}{n\left(P^{0}-P\right)}=\frac{1}{n_{m} C}+\frac{C-1}{n_{m} C} * \frac{P}{P^{0}}
$$

where $\mathrm{n}_{\mathrm{m}}$ is the monolayer capacity and $\mathrm{C}$ is a constant related exponentially to the heat of the first-layer adsorption. A plot of $\mathrm{P} / \mathrm{n}\left(\mathrm{P}^{0}-\mathrm{P}\right)$ against $\mathrm{P} / \mathrm{P}^{0}$ gives a straight line as shown in Figure 6B.
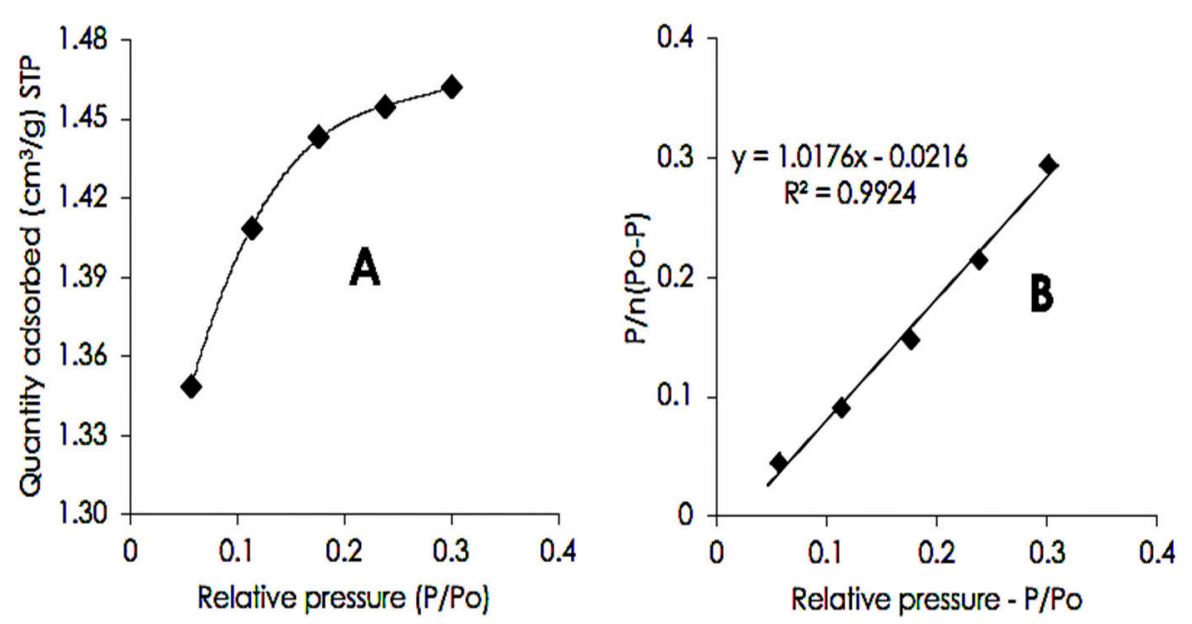

Figure 6: The porosity of lilac charcoal. A-Nitrogen adsorption isotherm. B-BET plot to determine the specific surface area. 
The specific surface area was calculated using Equation 6 [33].

$$
A_{B E T}=n_{m} * L * a_{m}
$$

where $\mathrm{L}$ is the Avogadro constant $\left(6.022 \times 10^{23} \mathrm{~mol}^{-1}\right)$ and $\mathrm{a}_{\mathrm{m}}$ is the molecular surface area of nitrogen. Figure $6 \mathrm{~B}$ reveals a slope of $1.017641 \pm 0.051371 \mathrm{~g} / \mathrm{cm}^{3}$ at standard temperature and pressure (STP), and the $y$-intercept was $-0.021624 \pm 0.010126 \mathrm{~g} / \mathrm{cm}^{3} \mathrm{STP}$. The value of $\mathrm{C}$ in Equations 3-5 was determined as -46.061 and the BET specific surface area was computed from Equations 3-6. Nitrogen at $77 \mathrm{~K}$ is assumed to be close-packed, so that $\mathrm{a}_{\mathrm{m}}\left(\mathrm{N}_{2}\right)$ is $0.162 \mathrm{~nm}^{2}$. Therefore, the computed BET specific surface area was $4.3706 \pm$ $0.2298 \mathrm{~m}^{2} / \mathrm{g}$.

\subsection{Free radicals on the charcoal surface}

\subsubsection{Radicals on fresh and cleaned charcoal}

The lilac charcoal used in this study was manufactured in the laboratory at $500{ }^{\circ} \mathrm{C}$, which achieves maximum reactivity and free radical production [34]. The normalized absorption peak area of the ESR spectrum of coals increases with pyrolysis temperature due to the greater abundance of active sites available for oxidation and hence increases the radical concentration [11]. In the same study, the g-values decreased with temperature, implying that the complexity of the radicals formed during carbonization decreases with temperature. High temperatures reduce the number of attached groups (oxygen and nitrogen among others) and the higher g-value coincides with an increase in the number of hetero atoms for organic radicals. This in turn expands the electron cloud, leading to an increase in both the g-value and the spin concentration.

We observed a higher spin concentration for acid-washed charcoal than untreated samples, but there were small changes in the observed g-values (Table 2). Similarly, the electron density of acid-washed coal was higher than that of untreated coal, coinciding with changes in g-value and line width attributed to the interaction between carbon radicals and paramagnetic inorganic constituents that make some carbon radicals unobservable [35]. Our trace element analysis (see above) revealed high levels of potassium, which can limit the concentration of radicals because potassium catalyses the conversion of bridges into char links during pyrolysis thus enhancing cross-linking and reducing char fluidity [12]. The formation of potassium-carbon bonds weakens the carbon-carbon bonds in aromatic rings and 
facilitates bond breaking at higher temperatures [12]. The line width of the nitrogen pyrolyzed charcoal subsequently exposed to air was $41.8 \mathrm{G}$ because pyrolysis makes the carbon more ordered like graphite. Variations in line width can be caused by the formation of disorganized carbon (producing narrow signals) [12] and organized carbon with conductive electrons (producing broad signals) [10].

An extraordinarily high concentration $\left(\sim 10^{20} / \mathrm{cm}^{3}\right)$ of the oxygen radicals $\mathrm{O}^{-}$and $\mathrm{O}_{2}^{-}$were formed when ceramics were heated in a dry oxygen atmosphere [36]. The total radical concentration reached $1.7 \times 10^{21} / \mathrm{cm}^{3}$ and the authors attributed this to the absorption of oxygen molecules which react with free oxygen to the radicals as follows in eqn. 7:

$$
\mathrm{O}_{2}(\text { atmosphere })+\mathrm{O}_{2}^{-}(\text {system }) \rightarrow \mathrm{O}^{-}(\text {system })+\mathrm{O}_{2}^{-}(\text {system })
$$

As shown in Figure 7, we observed a similar phenomenon in which oxygen was adsorbed onto the charcoal surface, forming radicals with a concentration of $7.06 \times 10^{19} \mathrm{spins} / \mathrm{g}$.

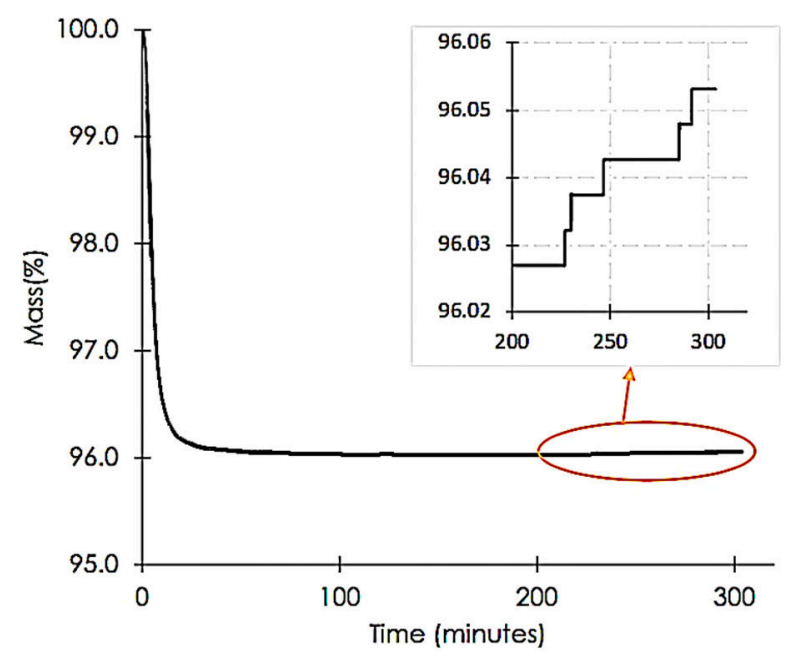

Figure 7: Mass gain following the exposure of fresh charcoal to air at $100^{\circ} \mathrm{C}$.

The rate of adsorption reached its maximum immediately upon the initial exposure of the cleaned char surface to air, which has previously been described as the early-peak phenomenon [37]. The adsorption rate then decreased with time at low temperatures, but nevertheless continued (Figure 3). The same observations have been reported for coals and low-temperature chars, indicating that oxygen adsorption capacities depend on the time allowed for chemisorption. Even after several days, the weight increase continued [38]. We observed similar behaviour at temperatures $<250^{\circ} \mathrm{C}$ for lilac charcoal. 
Table 2: ESR properties of the charcoal samples.

\begin{tabular}{|l|c|c|c|}
\hline \multicolumn{1}{|c|}{ Sample } & Line width $(\mathrm{G})$ & $\begin{array}{c}\text { Spin conc. } \\
\text { (spins/g) }\end{array}$ & g-value \\
\hline Normal (fresh) & 11.8 & $5.29 \times 10^{18}$ & 2.00481 \\
\hline Acid ( $\mathrm{HCl}$ ) washed & 11.9 & $3.49 \times 10^{19}$ & 2.00477 \\
\hline a Degassed with air & 11.6 & $7.06 \times 10^{19}$ & 2.00483 \\
\hline Degassed with $\mathrm{N}_{2}$ followed by air & 41.8 & $3.75 \times 10^{17}$ & 2.00260 \\
\hline
\end{tabular}

The results are for the main peak.

ESR analysis of fresh charcoal showed a single stable radical with a g-value of 2.00481

(Figure 8). Oxygen-centred radicals have g-values in the range 2.0038-2.0047 whereas carbon-centred radicals have g-values in the range 2.0025-2.003 [12] and peroxyl radicals have g-values in the range 2.038-2.003 [15].

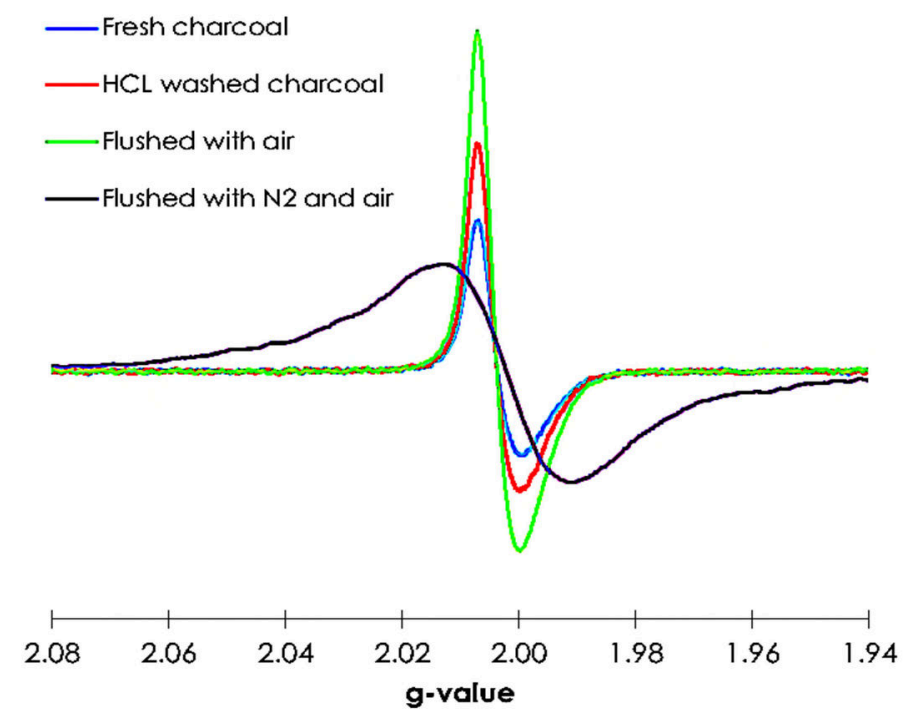

Figure 8: Free radical spectrum for fresh charcoal, acid-washed charcoal, charcoal flushed with air at $100^{\circ} \mathrm{C}$ and charcoal pyrolyzed in nitrogen and then flushed with air at $100^{\circ} \mathrm{C}$.

\subsubsection{Peroxyl radicals}

ESR analysis of fresh charcoal revealed a single radical, which was no longer detected after degassing the fresh charcoal with nitrogen (results not shown). Degassing the samples with nitrogen causes the radicals to be rearranged into non-radical species. However, exposure of the nitrogen-degassed charcoal to air at $100{ }^{\circ} \mathrm{C}$ formed a different radical (g-value 2.0026), presumably carbon-centred with oxygen heteroatoms. This means that if fresh charcoal is 
exposed to air alone at $100{ }^{\circ} \mathrm{C}$, we would expect to observe two radicals. The exposure of fresh charcoal to air resulted in a slight mass gain (Figure 7).

ESR analysis of the sample shown in Figure 7 initially showed a single radical with g-value of 2.00483 (Figure 8), which is similar to the g-value obtained with fresh charcoal. Reducing the noise of the ESR spectrum for this sample revealed four minor peaks superimposed on the major peak (Figure 9).

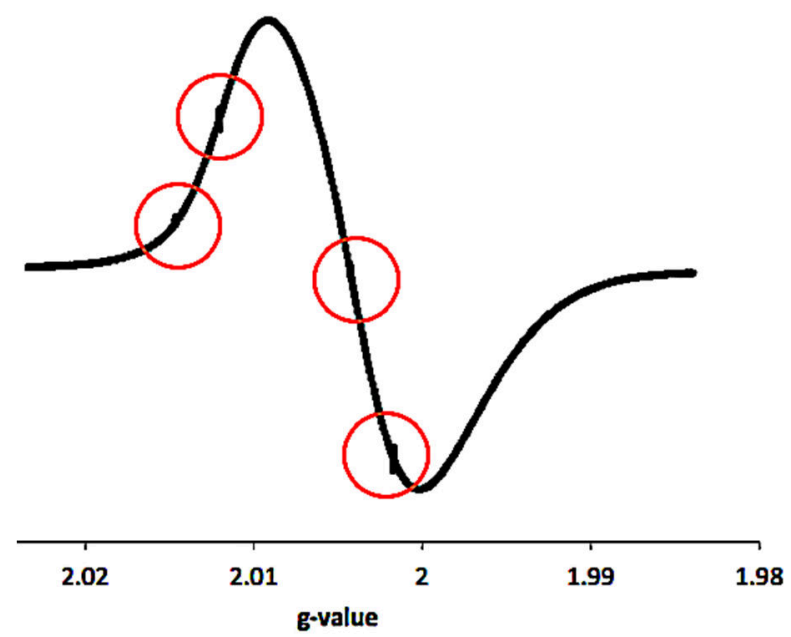

Figure 9: Peroxyl radicals are indicated by minor peaks superimposed on the major peak.

We initially assumed that the four peaks represented a single radical with multiple hyperfine line splitting, but this is unlikely according to the rules of hyperfine splitting and pascals triangle [16]. We therefore reduced the noise and magnified the spectrum further to observe the superimposed peaks more clearly (Figure 10). 


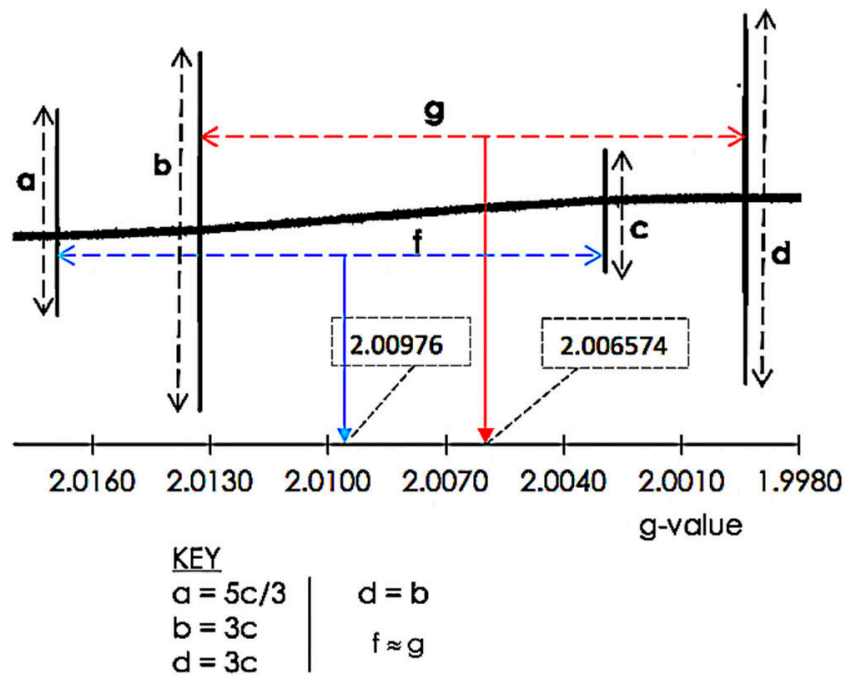

Figure 10: The ESR spectrum of the four peroxyl radicals.

\subsubsection{Assigning spectra to the radicals}

\subsection{Approach one: two peaks represent the same radical}

A closer inspection of Figure 10 revealed that the two high-intensity peaks appear to belong to one radical (g-value 2.00657) because they have approximately equal heights and constitute a 1:1 hyperfine split. Secondly, the peak-to-peak distance (hyperfine coupling constant) of the high-intensity peaks (average $2.142 \mathrm{mT}$ ) was similar to that of the lowintensity peaks (average $2.088 \mathrm{mT}$ ). This implies that the high-intensity radicals could be precursors of the low-intensity radicals. The low-intensity radicals (g-value 2.00976) are likely to be complex diradicals with many oxygen heteroatoms. We also observed that the intensity of the peaks was not the same during replicate runs, even under the same experimental conditions, but they oscillated within a defined magnitude (Supplementary Figure S-1). This shows how difficult it can be to analyse the peroxyl radical spectrum. However, pulse oscillations of the microwave frequency in the $\mathrm{kHz}$ range are likely to explain these spectral changes, because they cause pulsed changes in the intensities at reference points. Because the low-intensity peroxyl radicals were superimposed on the major peak, small changes in the normal pulse intensity affected the intensity of replicate runs under the same conditions, creating unevenness in the intensities of the peaks and distortions in the observed spectra (Supplementary data Figures S-2 to S-5). 


\subsection{Approach two: each peak is an independent radical}

The difference in the average hyperfine coupling distances between the high-intensity peaks and the low-intensity peaks (see above) resulted in a standard deviation between these two values of $0.270 \mathrm{mT}$. A two-tailed t-test distribution comparing the replicate hyperfine coupling distance values for the high-intensity and low-intensity radicals returned a $p$-value of 0.00044525 with a $95 \%$ confidence interval. This implies that the hyperfine coupling distances values are statistically different. Accordingly, each peak could represent a unique radical. The g-values and the peak heights of the peroxyl radicals are summarized in Table 3.

Table 3: Measurable parameters for the peroxyl radicals*

\begin{tabular}{|c|c|l|l|l|l|l|}
\hline & Run & 1 & 2 & 3 & 4 & Mean \pm SD \\
\hline $\begin{array}{c}\text { Centre field } \\
(\mathrm{mT})\end{array}$ & $\begin{array}{c}\text { MW freq. } \\
(\mathrm{MHz})\end{array}$ & 8966.321 & 8966.308 & 8966.305 & 8966.303 & \\
\hline \multirow{2}{*}{317.369} & PH (mT) & 1001 & 708 & 683 & 966 & $839.5 \pm 144.8$ \\
\cline { 2 - 7 } & g-value & 2.015499 & 2.015502 & 2.015502 & 2.015507 & $2.015502 \pm 0.000003$ \\
\hline \multirow{2}{*}{318.105} & PH (mT) & 1464 & 1187 & 1213 & 1373 & $1309.3 \pm 114.3$ \\
\cline { 2 - 7 } & g-value & 2.013806 & 2.013777 & 2.013798 & 2.013783 & $2.013791 \pm 0.000011$ \\
\hline \multirow{2}{*}{319.984} & PH (mT) & 775 & 1041 & 807 & 893 & $879 \pm 103$ \\
\cline { 2 - 7 } & g-value & 2.002007 & 2.002015 & 2.002014 & 2.002016 & $2.002013 \pm 0.000003$ \\
\hline \multirow{2}{*}{320.679} & PH (mT) & 1271 & 1480 & 1473 & 1262 & $1371.5 \pm 105.1$ \\
\cline { 2 - 7 } & g-value & 2.000685 & 2.00067 & 2.000668 & 2.000642 & $2.000666 \pm 0.000015$ \\
\hline
\end{tabular}

*These values are based on the assumption that each peak belongs to an independent radical.

\subsubsection{Simulation of peroxyl radical spectra}

In several studies involving the analysis of peroxyl radicals [13] the authors did not produce clearly defined spectra, making interpretation difficult [14], [39]. Although we likewise found our spectra difficult to interpret, we attempted to reproduce them using the isotropic simulation software JEOL v2000, assuming that the low-intensity peaks represented one radical and the high-intensity peaks another. Having expanded the individual peaks as described above (Figures B-2 to B-5) we used the software to simulate the ESR spectrum for the low-intensity peroxyl radicals, revealing the 1:2:1 hyperfine splitting pattern shown in Figure 11. We assumed that the high-intensity radicals are precursors of the low-intensity radicals and that both have the same characteristic parent structure, with the low-intensity radicals having undergone further oxidation to gain further heteroatoms (hence the higher g- 
vale). The high-intensity peaks are formed by hyperfine interaction, i.e. simpler spectra combining to form a more complex spectrum (data not shown).
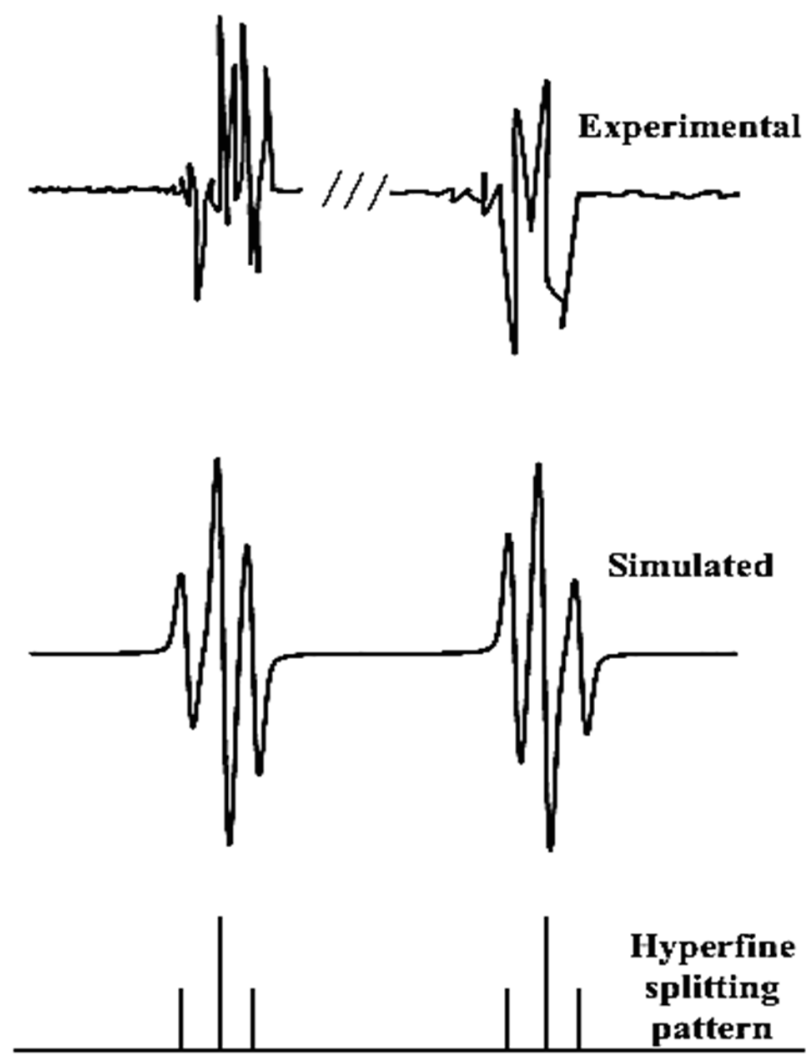

Figure 11: Simulation of the low-intensity peroxyl radicals.

\subsubsection{Reaction mechanisms forming peroxyl radicals}

Charcoal contains multiple functional groups and heteroatoms linked either to the aromatic structure or bridges [40]. The general structure of lilac charcoal is likely to be similar to that proposed elsewhere [29], including the presence of aromatic groups, carbonyl carbonates, carboxylic acids, lactones (with four or five carbons), ether bridges, cyclic ethers, cyclic anhydrides (with five or six carbons), quinones, phenols, alcohols, and ketone groups, as shown in Figure 12. 


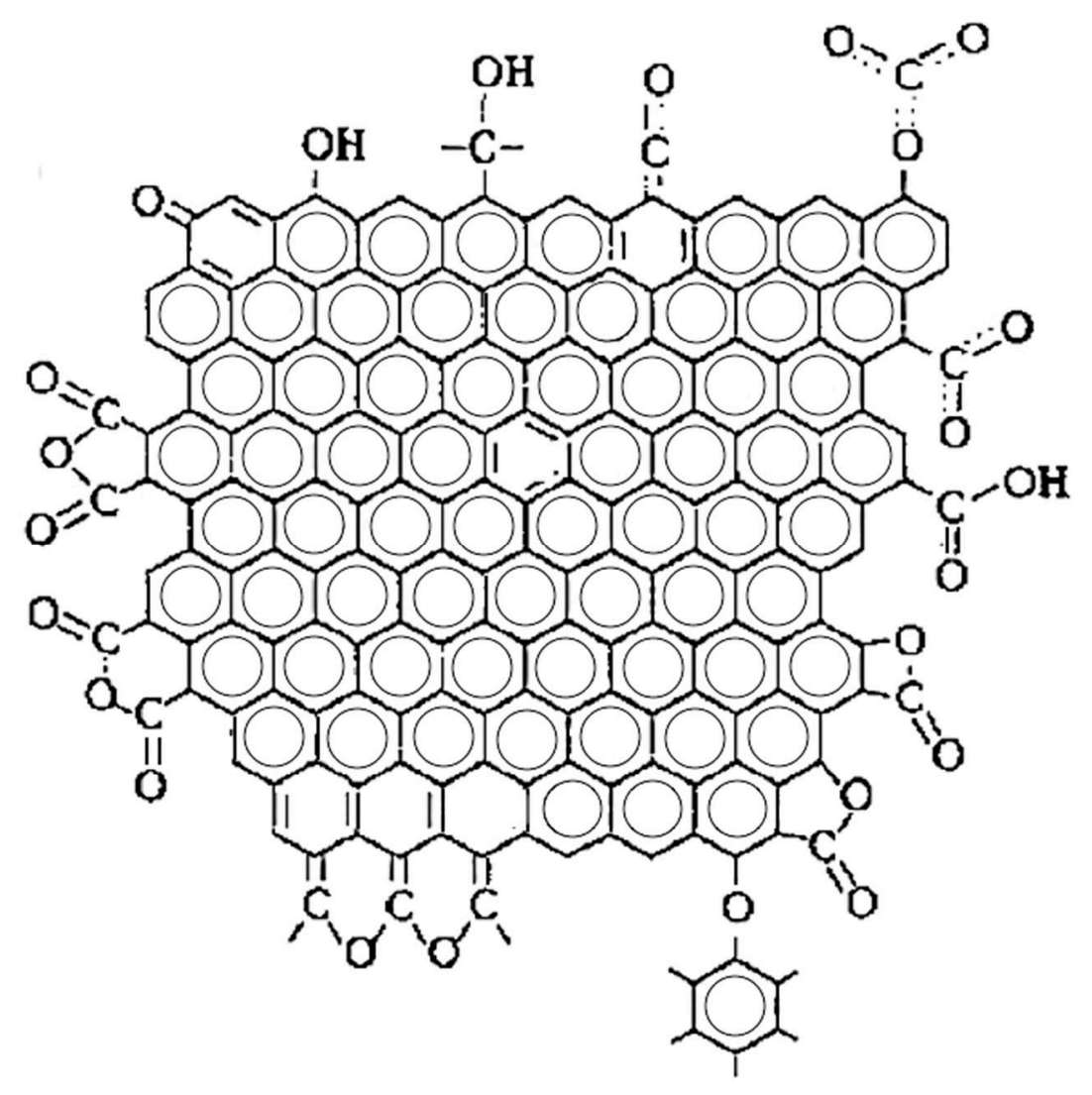

Figure 12: Structure of fresh charcoal showing functional groups, adapted from [29].

We found that peroxyl radicals do not form on activated carbons or cleaned carbon surfaces (i.e. carbon surfaces on charcoal that has been pyrolyzed in a nitrogen atmosphere to remove all the oxygen and nitrogen-containing functional groups as volatiles as well as converting free radicals into neutral groups). We cleaned the charcoal surfaces by pyrolysis in nitrogen and cooling in nitrogen to the desired temperature. Oxygen was adsorbed following exposure to air as explained above but ESR spectroscopy revealed radical species other than peroxyl radicals.

We propose that the peroxyl radicals are formed by the abstraction of hydrogen from hydroxyl groups within the carbon matrix. These types of peroxyl radicals are formed from carboxylic acids, phenols and alcohols. Other peroxyl radicals are formed when oxygen reacts with carbon-centred free radicals or exposed active carbons attached to other functional groups such as ether bridges and cyclic ethers. Based on the general structure of charcoal presented in Figure 12, and the proposed functional groups discussed above, the plausible reactions in the solid state are summarized in Figure 13. 


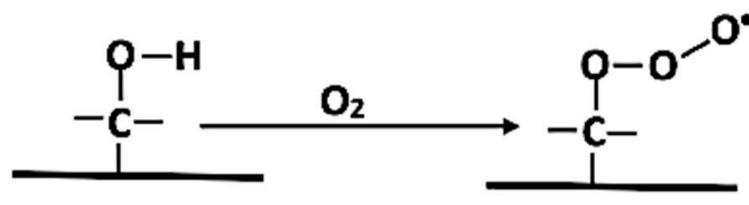

A
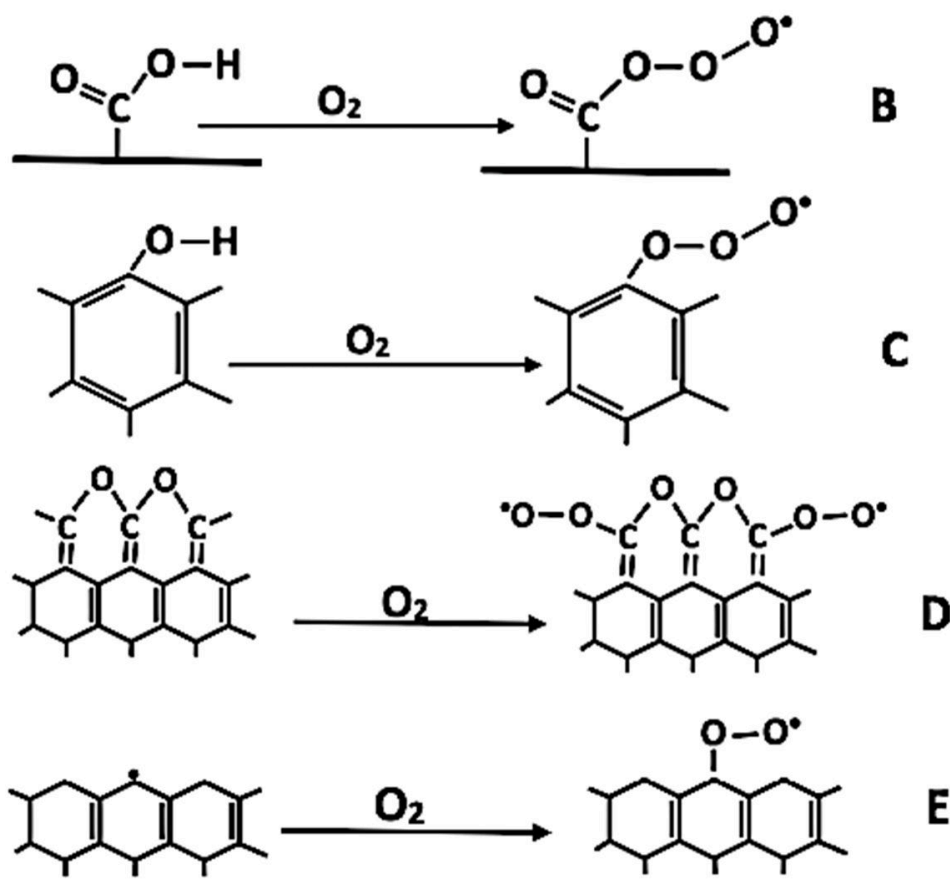

Figure 13: Proposed reaction for the formation of peroxyl radicals (potential intermediate steps omitted).

Oxygen can form complexes accompanied by a significant increase in the $\mathrm{O}-\mathrm{O}$ interaction distance and a corresponding decrease in the $\mathrm{v}(\mathrm{O}-\mathrm{O})$ vibrational stretching frequency. This may reflect the transfer of electrons from the carbon atop into the anti-bonding orbitals of $\mathrm{O}_{2}$ to form the O-O bond [41].

\subsubsection{Activated and semi-activated carbons}

The normal (fresh) charcoal was degassed with nitrogen while heating from 30 to $750{ }^{\circ} \mathrm{C}$ and then cooled in nitrogen to $30^{\circ} \mathrm{C}$. ESR analysis of this sample (results not shown) did not reveal the presence of radicals. During the degassing process, oxygen and nitrogen species [29] are lost from the char surfaces as volatile gaseous products, and the carbon-carbon centred radicals recombine to form non-radical products [12]. Other volatiles that are evolved include radicals such as ${ }^{\bullet} \mathrm{OH},{ }^{\bullet} \mathrm{CH}_{3}$ and ${ }^{\bullet} \mathrm{OCH}_{3}$. During the loss of volatile matter, the volatile matter/fixed carbon ratio declines as aromaticity increases [40]. 
We analysed the activated carbons by ESR spectroscopy for comparison and detected no signals at all, even after degassing in nitrogen and exposure to air for $30 \mathrm{~min}$ at $5 \mathrm{ml} / \mathrm{min}$ and $100{ }^{\circ} \mathrm{C}$. The same results were observed when lilac charcoal was pyrolyzed in nitrogen to $750{ }^{\circ} \mathrm{C}$ and cooled in nitrogen to room temperature, confirming the unreactive nature of activated carbons in the presence of weak oxidants like air at low temperatures. Similarly, DRIFT spectroscopy revealed no bands even though gasification was occurring when Saran carbon (vinylidene chloride/vinyl chloride copolymer) was activated in hydrogen and then exposed to $20 \% \mathrm{O}_{2}$, implying that no oxygen functional groups were formed [29]. Activating charcoal removes impurities and also removes oxygen from the carbon surface [29].

The adsorption of oxygen by the acid-washed charcoal was limited compared to the fresh charcoal. When pyrolyzed in nitrogen and then exposed to air at $100{ }^{\circ} \mathrm{C}$, the fresh charcoal registered an ESR signal with a clear spectrum (after magnification). When the same treatment was applied to acid-washed charcoal, no ESR signal was detected, implying a weaker adsorption capacity for oxygen in the air, leading to fewer radicals. Mineral elements appear to enhance the ability of charcoal to absorb materials that form radicals. For example, activated carbons washed with $\mathrm{HCL}$ did not absorb $\mathrm{NO}_{2}$ and $\mathrm{H}_{2} \mathrm{~S}$ efficiently, possibly because the reaction between the molecules of the adsorbed gas and metal oxides in the mineral fraction led to the formation of nitrates and sulfides [42]. Our observation that fresh charcoal can adsorb more oxygen and form more radicals than acid-washed charcoal may reflect the same phenomenon, involving the formation of mineral oxide linkages within the pore structure of the charcoal.

\section{CONCLUSIONS}

In this study, we characterized lilac charcoal to determine its reactivity, oxygen adsorption capacity, porosity, and ability to form free radicals, resulting in the following conclusions:

1. Lilac charcoal is a microporous material with a specific surface area of $4.3706 \mathrm{~m}^{2} / \mathrm{g}$.

2. It is a highly reactive material with low ignition temperatures $\left(250-300{ }^{\circ} \mathrm{C}\right)$.

3. It burns quickly within a narrow combustion temperature range $\left(300-520^{\circ} \mathrm{C}\right)$.

4. The production of lilac charcoal from woody biomass via pyrolysis produces large amounts of free radicals, in the order of $10^{18} \mathrm{spins} / \mathrm{g}$. 
5. However, acid washing (with $\mathrm{HCl}$ in our experiments) or flushing with nitrogen at high temperatures removes and/or inactivates the free radicals.

6. Exposure of lilac charcoal to air forms persistent oxygen-centred free radicals.

7. The ability of lilac charcoal to form persistent peroxyl radicals combined with the low ignition temperatures and narrow oxidation temperature range can be exploited for downstream applications such as carbon catalysis, the manufacture of highly reactive materials, and the adsorption of specific target organic species. Lilac charcoal can also be used for co-firing applications.

\section{ACKNOWLEDGMENTS}

The authors thank the Gas Safety Trust UK and Boat Safety Scheme UK for sponsoring this work. We also acknowledge the experimental support provided by Nathan Flood, Ian Wilson, Peter Wilkinson and Nicola Darcy.

\section{COMPETING STATEMENT}

We have no interests to declare

\section{DATA STATEMENT}

Supporting information is provided in the supplementary data

\section{REFERENCES}

[1] A. Zolin, A. Jensen, P. A. Jensen, F. Frandsen, and K. Dam-Johansen, "The Influence of Inorganic Materials on the Thermal Deactivation of Fuel Chars," Energy \& Fuels, vol. 15, no. 5, pp. 1110-1122, Sep. 2001.

[2] R. E. Mitchell, P. A. Campbell, and L. Ma., "Characterization of coal and biomass conversion behaviors in advanced energy systems," in GCEP Research Symposium, 2005, pp. 1-13.

[3] M. Morin, S. Pécate, and M. Hémati, "Kinetic study of biomass char combustion in a low-temperature fluidized bed reactor," Chem. Eng. J., vol. 331, no. August, pp. 265277,2018 
[4] A. Nyombi, M. R. Williams, and R. Wessling, "Determination of Kinetic Parameters and Thermodynamic properties of Ash (fraxiuns) sawdust slow pyrolysis using Thermogravimetric Analysis," Energy Sources, Part A Recover. Util. Environ. Eff., vol. 40, no. 22, pp. 2660-2670, 2018.

[5] F. X. Collard and J. Blin, "A review on pyrolysis of biomass constituents: Mechanisms and composition of the products obtained from the conversion of cellulose, hemicelluloses and lignin,” Renew. Sustain. Energy Rev., vol. 38, pp. 594-608, 2014.

[6] E. Apaydin-Varol and A. E. Pütün, "Preparation and characterization of pyrolytic chars from different biomass samples," J. Anal. Appl. Pyrolysis, vol. 98, pp. 29-36, 2012.

[7] J. W. Patric and E. Arnold, Porosity of Carbons, 1st ed. London: British Library, 1995.

[8] J. Dollimore, C. M. Freedman, B. H. Harrison, and D. F. Quinn, "Surface complexes on carbon-I. A preliminary investigation of surface oxygen complex on a non-graphitic carbon," Carbon N. Y., vol. 8, no. 5, pp. 587-596, 1970.

[9] M. J. Antal and M. Grønli, "The Art, Science, and Technology of Charcoal Production," Ind. Eng. Chem. Res., vol. 42, no. 8, pp. 1619-1640, 2003.

[10] J. Bourke, M. Manley-Harris, C. Fushimi, K. Dowaki, T. Nunoura, and M. J. Antal, "Do all carbonized charcoals have the same chemical structure? 2. A model of the chemical structure of carbonized charcoal," Ind. Eng. Chem. Res., vol. 46, no. 18, pp. 5954-5967, 2007.

[11]T. Chang, Q. Guo, H. Hao, B. Wu, and Y. Yang, "Formation of radicals in coal pyrolysis examined by electron spin resonance," AIP $A d v$., vol. 7, no. 9, 2017.

[12] A. Trubetskaya, P. A. Jensen, A. D. Jensen, P. Glarborg, F. H. Larsen, and M. L. Andersen, "Characterization of free radicals by electron spin resonance spectroscopy in biochars from pyrolysis at high heating rates and at high temperatures," Biomass and Bioenergy, vol. 94, pp. 117-129, 2016.

[13] K. U. Ingold, "Peroxy Radicals," Acc. Chem. Res., vol. 2, no. 1, p. 5975, 1969.

[14] U. Molteni, F. Bianchi, F. Klein, I. El Haddad, C. Frege, M. J. Rossi, J. Dommen, and U. Baltensperger, "Formation of highly oxygenated organic molecules from 
aromatic \ncompounds," Atmos. Chem. Phys. Discuss., no. December, pp. 1-39, 2016.

[15]D. C. McCain and W. E. Palke, "Theory of electron spin g-values for peroxy radicals," $J$. Magn. Reson., vol. 20, no. 1, pp. 52-66, 1975.

[16] V. Chechik, E. Cater, and D. Murphy, Electron Paramagnetic Resonance. Oxford, U.K: Oxford University Press, 2016.

[17] J.-E. Jung, S. Liguori, A. D. Jew, G. E. Brown, and J. Wilcox, “Theoretical and experimental investigations of mercury adsorption on hematite surfaces," J. Air Waste Manage. Assoc., vol. 68, no. 1, pp. 39-53, Jan. 2018.

[18]H. E. Kissinger, "Variation of peak temperature with heating rate in differential thermal analysis," J. Res. Natl. Bur. Stand. (1934)., vol. 57, no. 4, p. 217, 1956.

[19] S. S. Idris, N. A. Rahman, K. Ismail, A. B. Alias, Z. A. Rashid, and M. J. Aris, "Investigation on thermochemical behavior of low rank Malaysian coal, oil palm biomass and their blends during pyrolysis via thermogravimetric analysis (TGA)," Bioresour. Technol., vol. 101, no. 12, pp. 4584-4592, 2010.

[20] M. Heydari, M. Rahman, and R. Gupta, "Kinetic study and thermal decomposition behavior of lignite coal," Int. J. Chem. Eng., vol. 2015, 2015.

[21]F. H. Joseph and W. A. Leo, "A quick, direct method for the determination of activation energy from thermogravimetric data," Polym. Lett., vol. 4, no. 5, pp. 323-328, 1966.

[22] T. Ozawa, "A New Method of Analyzing Thermogravimetric Data," Bull. Chem. Soc. Jpn., vol. 38, no. 11, pp. 1881-1886, 1965.

[23] J. Zsakó and H. E. Arz, "Kinetic analysis of thermogravimetric data," J. Therm. Anal., vol. 6, no. 6, pp. 651-656, 1974.

[24] S. Mallakpour and M. Taghavi, "The Accuracy of Approximation Equations in the Study of Thermal Decomposition Behaviour of Some Synthesized Optically Active Polyamides," Iran. Polym. J. (English Ed., vol. 18, no. 11, pp. 857-872, 2009.

[25] A. Raj, S. Y. Yang, D. Cha, R. Tayouo, and S. H. Chung, "Structural effects on the oxidation of soot particles by O2: Experimental and theoretical study," Combust. Flame, 
vol. 160, no. 9, pp. 1812-1826, 2013.

[26]P. J. F. Harris, "Fullerene-like models for microporous carbon,” J. Mater. Sci., vol. 48, no. 2, pp. 565-577, Jan. 2013.

[27] R. W. Froberg, P. Corporation, and R. Essenhigh, "Reaction order and activation energy of carbon oxidation during internal burning," Symp. Combust., vol. 17, no. 1, pp. 179 $187,1979$.

[28] A. Nyombi, M. Williams, and R. Wessling, "Determination of kinetic parameters and thermodynamic properties for ash (Fraxinus) wood sawdust slow pyrolysis by thermogravimetric analysis," Energy Sources, Part A Recover. Util. Environ. Eff., vol. 40, no. 22, pp. 2660-2670, Aug. 2018.

[29] E. P. Fanning and M. A. Vannice, "A Drifts Study of the Formation of Surface Groups on Carbon By Oxidation," Carbon N. Y., vol. 31, no. 5, pp. 721-730, 1991.

[30] J. L. Figueiredo and M. F. R. Pereira, "The role of surface chemistry in catalysis with carbons," Catal. Today, vol. 150, no. 1-2, pp. 2-7, 2010.

[31] M. Ciobanu, A. M. Lepadatu, and S. Asaftei, "Chemical and Electrochemical Studies of Carbon Black Surface by Treatment with Ozone and Nitrogen Oxide," in Proceedings of the International Conference on Diamond and Carbon Materials Chemical, 2016, vol. 3, pp. S252-S257.

[32] K. C. Salooja, "Studies of combustion processes leading to ignition in hydrocarbons," Combust. Flame, vol. 9, no. June, pp. 121-129, 1965.

[33] K. Sing, "Physisorption of Gases by Porous Carbons," in Porosity in Carbons, 1st ed., London, 1995, pp. 49-64.

[34] T. Urbanski, S. Benbenek, S. Bedynski, and A. Wasilewski, "Free radicals in charcoal and the combustion of compositions containing charcoal," Explosivstoffe, vol. 1, pp. 9$11,1970$.

[35] B. G. Silbernagel, L. A. Gebhard, R. A. Flowers, and J. W. Larsen, "Demineralization effects on the EPR properties of Argonne premium coals," Energy \& Fuels, vol. 5, no. 4, pp. 561-568, 1991. 
[36] H. Hosono and H. Masahiro, "Functional Cultivation of Transport Oxides Utilising Natural and Artificial NAnostructures," in Nanomaterials: From Research to Application, 2006, pp. 27-30.

[37]P. A. Campbell and R. E. Mitchell, "The impact of the distributions of surface oxides and their migration on characterization of the heterogeneous carbon-oxygen reaction," Combust. Flame, vol. 154, no. 1-2, pp. 47-66, 2008.

[38] M. Heinz-Jurgen and H. van H. Karl, "Porosity and Thermal Reactivity," in Porosity in Carbons, 1st ed., London, 1995, pp. 131-148.

[39] S. Richters, H. Herrmann, and T. Berndt, "Different pathways of the formation of highly oxidized multifunctional organic compounds (HOMs) from the gas-phase ozonolysis of ß-caryophyllene," Atmos. Chem. Phys., vol. 16, no. 15, pp. 9831-9845, 2016.

[40]B. Miller and D. Tillman, Combustion Engineering Issues for Solid Fuel Systems, 1st ed. Califonia: Academic Press, 2008.

[41] N. Greenwood, N and A. Earnshaw, "Oxygen," in Chemistry of the Elements, 2nd ed., N. Greenwood, N and A. Earnshaw, Eds. London: Reed Educational and Professional Publishing, 1997, pp. 600-640.

[42]P. Nowicki, "The effect of mineral matter on the physicochemical and sorption properties of brown coal-based activated carbons," Adsorption, vol. 22, no. 4-6, pp. 561$569,2016$. 